\title{
Ir-Catalyzed Allylic Amination and Etherification
}

Metal-Catalyzed

Asymmetric

Synthesis and

Stereoselective

Reactions

Key Words

allylic amination phosphoramidite iridium<smiles>[R]c1ccccc1[C@H](C)N([C@H](C)c1ccccc1[R])P(Oc1ccc2ccccc2c1-c1c(OC)ccc2ccccc12)Oc1cccc2ccccc12</smiles>

Significance: This system allows for highly stereoselective intramolecular allylic aminations and etherifications as well as intermolecular allylic amination followed by intramolecular cyclization (shown). Low catalyst loading (2 mol\%), and fast reaction times make this a suitable system for the synthesis of various ring sized $\mathrm{N}$-heterocycles.
Comment: The versatility of this system is exceptional. Application for the synthesis of useful chiral $\mathrm{N}$-heterocycles, O-heterocycles, and allylic amines, all important building blocks, makes this protocol potentially very useful. The ability to form various ring sizes, as well as simple allylic amination, shows the effectiveness of this scheme. Particularly noteworthy is that several useful chiral C-2 symmetric amines can be synthesized enantioselectively. Previously, these compounds were prepared via a number of steps. 